\title{
Use of perioperative hydroxyethyl starch $6 \%$ and albumin $5 \%$ in elective joint arthroplasty and association with adverse outcomes: a retrospective population based analysis
}

\author{
Mathias Opperer, ${ }^{1}$ Jashvant Poeran, ${ }^{2}$ Rehana Rasul,, ${ }^{3}$ Madhu Mazumdar, ${ }^{3}$ Stavros G Memtsoudis ${ }^{4}$
}

For numbered affiliations see end of article.

Correspondence to:

S G Memtsoudis Department of

Anesthesiology, Hospital for Special Surgery, New York, NY 10021, USA memtsoudiss@hss. edu

Additional material is published online only. To view please visit the journal online (http:// dx.doi.org/10.1136/BMJ.h1567) Cite this as: BMJ 2015;350:h1567 doi:10.1136/bmj.h1567

Accepted: 17 February 2015

\section{ABSTRACT}

OBJECTIVE

To determine whether the perioperative use of hydroxyethyl starch $6 \%$ and albumin $5 \%$ in elective joint arthroplasties are associated with an increased risk for perioperative complications.

DESIGN

Retrospective cohort study of population based data between 2006 and 2013.

SETTING

Data from 510 different hospitals across the United States participating in the Premier Perspective database.

\section{PARTICIPANTS}

1051441 patients undergoing elective total hip and knee arthroplasties.

EXPOSURES

Perioperative fluid resuscitation with hydroxyethyl starch $6 \%$ or albumin $5 \%$, or neither.

MAIN OUTCOME MEASURES

Acute renal failure and thromboembolic, cardiac, and pulmonary complications.

RESULTS

Compared with patients who received neither colloid, perioperative fluid resuscitation with hydroxyethyl starch $6 \%$ or albumin $5 \%$ was associated with an increased risk of acute renal failure (odds ratios 1.23 (95\% confidence interval 1.13 to 1.34 ) and 1.56 (1.36 to 1.78), respectively) and most other complications. A recent decrease in hydroxyethyl starch $6 \%$ use was noted, whereas that of albumin $5 \%$ increased.

\section{WHAT IS ALREADY KNOWN ON THIS TOPIC}

Fluid resuscitation with hydroxyethyl starch has been associated with increased risks of (markers for) acute kidney injury and renal replacement therapy in septic or critically ill patients, which have led to warnings by governmental agencies

Albumin, as a possible perioperative alternative, has also been linked to increased complications

Large scale trials and observational studies to assess the outcomes and practice associated with these specific perioperative colloids are lacking

\section{WHAT THIS STUDY ADDS}

Our analysis of a large, national, claims based database from the United States found that perioperative use of both hydroxyethyl starch $6 \%$ and albumin $5 \%$ were associated with a higher risk of acute renal failure and of other complications after total hip and knee arthroplasties

Recently, in the US the use of hydroxyethyl starch $6 \%$ in elective orthopedic surgery decreased, whereas use of albumin $5 \%$ increased

These results question the widespread perioperative use of hydroxyethyl starch $6 \%$ and albumin $5 \%$

\section{CONCLUSIONS}

Similar to studies in critically ill patients, we showed that use of hydroxyethyl starch $6 \%$ was associated with an increased risk of acute renal failure and other complications in the elective perioperative orthopedic setting. This increased risk also applied to albumin $5 \%$. These findings raise questions regarding the widespread use of these colloids in elective joint arthroplasty procedures.

\section{Introduction}

The optimal choice of resuscitation fluid has been the subject of intense debate for decades, with definitive conclusions largely lacking. ${ }^{12}$ Several recent publications cautioned that hydroxyethyl starches might be associated with an increased risk of acute kidney injury and renal replacement therapy, especially in septic or critically ill patients. ${ }^{3-7}$ In June 2013 the US Food and Drug Administration (FDA) released a warning concerning the use of hydroxyethyl starches in patients with sepsis, impaired renal function, or coagulopathies. ${ }^{8}$ Concurrently, the European Medicines Agencies (EMA) Pharmacovigilance Risk Assessment Committee restricted the indications for hydroxyethyl starch and called for further studies evaluating the risk of complications in elective surgery and trauma patients. ${ }^{9}$ Others have questioned the choice of hydroxyethyl starch solutions for volume resuscitation in any patient population. ${ }^{11} 11$ To date, a paucity of data exists regarding the safety of hydroxyethyl starch in the elective, perioperative setting, with advocates and opponents debating their points. ${ }^{1213}$ Further, possible alternatives with long track records, such as albumin, have not been without criticism. Albumin, like hydroxyethyl starch, has been associated with impaired coagulation and increased blood product transfusion rates after cardiac surgery ${ }^{14}$ and has failed to show that it reduces mortality among critically ill, hypovolemic patients. ${ }^{15}$

We set out to investigate the perioperative use of hydroxyethyl starch $6 \%$ and albumin 5\% (for convenience further on referenced as hydroxyethyl starch and albumin), and their association with adverse outcomes in elective and largely standardized procedures such as lower extremity joint arthroplasties. For this purpose we used a large, nationwide, claims based database including information provided by over 500 different US hospitals. We hypothesized that hydroxyethyl starch and albumin might be associated with increased odds for perioperative complications. While observational databases cannot inform us on causal relationships between hydroxyethyl starch or albumin and safety outcomes, associations observed might provide valuable 
information that can inform randomized trials and subsequent prospective studies.

\section{Material and methods \\ Data source and study design}

We accessed the Premier Perspective database (Premier, Charlotte, NC) ${ }^{16}$ for hospital discharges from January 2006 to December 2013 to establish this cohort. Apart from ICD-9 cm (international classification of diseases, ninth revision, clinical modification) codes and Current Procedural Terminology codes this claims-based dataset provides standardized billing items. ICD-9 codes and Current Procedural Terminology codes are used to identify patient diagnoses and characteristics of patient encounters (such as procedures) as they provide the basis for reimbursement. The process is discussed in more detail elsewhere. ${ }^{17}$

Before data are incorporated in the Premier database the vendor performs a rigorous data validation and quality assurance process. This process involves a seven-step integrity analysis, followed by approximately 150 sampling and statistical validity and integrity assurance crosschecks on all hospital supplied data. For standardized codes, such as ICD-9 and Current Procedural Terminology codes, the codes are ascertained to be valid for the time period the patient record is reported. The dataset is increasingly used by a variety of study groups addressing clinical questions. ${ }^{18} 19$

As the Premier Perspective dataset meets the requirements of de-identification as specified under the Health Insurance Portability and Accountability Act, this study was exempt from individual consent requirements by the Hospital for Special Surgery Institutional Review Board (No 2012-050-CR2). Before data retrieval and analysis, we established a statistical analysis plan outlining the cohort, the hypothesis, and primary outcomes.

\section{Study sample}

The study cohort was defined as all adult ( $\geq 18$ years old) inpatients undergoing either elective primary total hip or knee arthroplasty, as identified by ICD-9 cm codes 81.51 and $81.54(n=1062931)$. We excluded patients with missing information on sex $(n=69)$ or discharge status ( $\mathrm{n}=498$ ) and those with multiple arthroplasties during a single admission $(n=212)$. We defined perioperative use of hydroxyethyl starch or albumin as use on the day of surgery and the day after surgery and excluded patients who were billed for either hydroxyethyl starch or albumin before or after this period ( $\mathrm{n}=4033)$. This step was taken to ensure a high probability that administration of colloids was used for perioperative fluid resuscitation. Finally, patients who received both solutions $(n=561)$ or albumin $25 \%(n=1476)$ or for whom information on the dose of these items was missing $(n=4641)$ were excluded.

\section{Study variables}

The use of either hydroxyethyl starch or albumin was determined by standardized billing items identified as Hetastarch 6\%, Hespan (500 mL), or Albumin VL 5\%
(100-1000 mL). In addition, total hydroxyethyl starch and albumin dosages per patient were also determined. The database further provides patient demographic variables (age, sex, and ethnicity (white, black, Hispanic, other)); healthcare related variables (insurance type (commercial, Medicaid, Medicare, uninsured, other), hospital location (rural, urban), hospital size $(<300$, 300-499, $\geq 500$ beds), hospital teaching status, mean annual number of procedures per hospital); and procedure related variables (type of procedure (total hip arthroplasty, total knee arthroplasty), year of procedure, use of a blood product transfusion). The type of anesthesia (general, neuraxial, general and neuraxial combined, other, unknown) and the use of a peripheral nerve block were determined from billing and procedural codes as has been previously reported by our study group. ${ }^{20}$ To measure overall comorbidity burden, the Quan algorithms for the Charlson comorbidity index was used. ${ }^{21}$ Originally, the Charlson comorbidity index, weighted on comorbidity severity and number, was designed to predict mortality. The definition of each comorbidity was later adapted to ICD-9 codes by Deyo et al, ${ }^{22}$ and Quan et al updated the index in 2005 with new definitions and weights ${ }^{21}$ because ICD-9 codes and the predictive value of mortality given specific comorbidities had changed.

Individual comorbidity groups were reported according to the Elixhauser comorbidity grouping ${ }^{23}$ as well as the presence of sleep apnea, as this disease has been reported to affect perioperative outcomes but is not included in the grouping.

Primary outcome variables were acute renal failure, thromboembolic complications, cardiac complications, pulmonary complications, and a combined complications variable. Combined complications were defined as having at least one indication of acute renal failure, thromboembolic events, cardiac complications, atrial fibrillation, pulmonary complications, cerebrovascular events, gastrointestinal complications, or in-hospital mortality. Secondary outcome variables were in-hospital mortality, admission to an intensive care unit, use of mechanical ventilation, length of hospital stay, and the cost of hospitalization. The respective ICD-9 $\mathrm{cm}$ codes and definitions are listed in appendix 1 in the online data supplement.

\section{Statistical methods}

Univariable analysis-The use of hydroxyethyl starch, albumin, or neither colloid by study variables was described using means and standard deviations for continuous variables and percentages for categorical variables. Univariable associations were assessed using $x^{2}$ and one-way analysis of variance tests for categorical and continuous variables, respectively (that is, overall testing between two variables). Median and interquartile range were reported for length of stay, cost of hospitalization, and the Charlson comorbidity index because of their skewed distribution, and significance between groups was measured using the Kruskal-Wallis test. Multilevel logistic regression analysis-To measure the multivariable association between use of hydroxyethyl starch, albumin, or neither and primary outcomes, we 


\begin{tabular}{|c|c|c|c|}
\hline & $\begin{array}{l}\text { Hydroxyethyl starch } \\
(\mathrm{n}=43732)\end{array}$ & $\begin{array}{l}\text { Albumin } \\
(\mathrm{n}=8022)\end{array}$ & $\begin{array}{l}\text { Neither } \\
(\mathrm{n}=999687)\end{array}$ \\
\hline \multicolumn{4}{|l|}{ Patient demographics } \\
\hline Mean (SD) age (years) & $65.4(11.3)$ & $66.4(11.7)$ & $65.8(10.8)$ \\
\hline \multicolumn{4}{|l|}{ Sex: } \\
\hline Women & $25910(59.2)$ & $4878(60.8)$ & $607626(60.8)$ \\
\hline Men & $17822(40.8)$ & 3144 (39.2) & 392061 (39.2) \\
\hline \multicolumn{4}{|l|}{ Ethnicity: } \\
\hline White & $32880(75.2)$ & 6326 (78.9) & 759055 (75.9) \\
\hline Black & $2560(5.9)$ & $698(8.7)$ & $70850(7.1)$ \\
\hline Hispanic & $1249(2.9)$ & $156(1.9)$ & 12609 (1.3) \\
\hline Other & $7043(16.1)$ & $842(10.5)$ & $157173(15.7)$ \\
\hline
\end{tabular}

\section{Healthcare related}

Insurance type:

\begin{tabular}{llll}
\hline Commercial & $16979(38.8)$ & $2819(35.1)$ & $381301(38.1)$ \\
\hline Medicaid & $1260(2.9)$ & $277(3.5)$ & $26607(2.7)$ \\
\hline Medicare & $24213(55.4)$ & $4666(58.2)$ & $552930(55.3)$ \\
\hline Uninsured & $289(0.7)$ & $57(0.7)$ & $5339(0.5)$ \\
\hline Other & $991(2.3)$ & $203(2.5)$ & $33510(3.4)$ \\
\hline Hospital location: & & \\
\hline Rural & $5204(11.9)$ & $380(4.7)$ & $118773(11.9)$ \\
\hline$\quad$ Urban & $38528(88.1)$ & $7642(95.3)$ & $880914(88.1)$ \\
\hline Hospital size (No of beds): & & & \\
\hline$<300$ & $16235(37.1)$ & $1802(22.5)$ & $367449(36.8)$ \\
\hline $\begin{array}{l}\text { 300-499 } \\
\geq 500\end{array}$ & $12750(29.2)$ & $3773(47.0)$ & $368284(36.8)$ \\
\hline Hospital teaching status: & $14747(33.7)$ & $2447(30.5)$ & $263954(26.4)$ \\
\hline Non-teaching & & & \\
\hline Teaching & $21742(49.7)$ & $4303(53.6)$ & $610306(61.1)$ \\
\hline $\begin{array}{l}\text { Mean (SD) annual No of } \\
\text { procedures per hospital }\end{array}$ & $21990(50.3)$ & $3719(46.4)$ & $389381(39.0)$ \\
\hline Procedur related & $869.4(969.9)$ & $611.1(355.5)$ & $732.5(686.4)$ \\
\hline
\end{tabular}

\section{Procedure related}

\begin{tabular}{llll}
\hline Median (IQR) dose $(\mathrm{mL})$ & $500(500-500)$ & $500(250-500)$ & - \\
\hline $\begin{array}{l}\text { Type of procedure: } \\
\text { Total hip arthroplasty }\end{array}$ & $23709(54.2)$ & $5451(68.0)$ & $308994(30.9)$ \\
\hline $\begin{array}{l}\text { Total knee arthroplasty } \\
\text { Type of anesthesia: }\end{array}$ & $20023(45.8)$ & $2571(32.0)$ & $690693(69.1)$ \\
\hline General & $22767(52.1)$ & $4814(60.0)$ & $581822(58.2)$ \\
\hline Neuraxial & $6811(15.6)$ & $921(11.5)$ & $105075(10.5)$ \\
\hline $\begin{array}{l}\text { General and neuraxial } \\
\text { combined }\end{array}$ & $8479(19.4)$ & $889(11.1)$ & $110523(11.1)$ \\
\hline Other & $3010(6.9)$ & $564(7.0)$ & $110240(11.0)$ \\
\hline Unknown & $2665(6.1)$ & $834(10.4)$ & $92027(9.2)$ \\
\hline Year of procedure: & & & \\
\hline 2006 & $4114(9.4)$ & $811(10.1)$ & $95909(9.6)$ \\
\hline 2007 & $4130(9.4)$ & $601(7.5)$ & $103524(10.4)$ \\
\hline 2008 & $4625(10.6)$ & $635(7.9)$ & $108372(10.8)$ \\
\hline 2009 & $5587(12.8)$ & $770(9.6)$ & $123832(12.4)$ \\
\hline 2010 & $6662(15.2)$ & $935(11.7)$ & $136867(13.7)$ \\
\hline 2011 & $6675(15.3)$ & $1136(14.2)$ & $143458(14.4)$ \\
\hline 2012 & $7060(16.1)$ & $1336(16.7)$ & $146869(14.7)$ \\
\hline 2013 & $4879(11.2)$ & $1798(22.4)$ & $140856(14.1)$ \\
\hline Use of peripheral nerve block & $11740(26.8)$ & $1113(13.9)$ & $174685(17.5)$ \\
\hline Use of transfusions & $10704(24.5)$ & $2716(33.9)$ & $152373(15.2)$ \\
\hline SD & &
\end{tabular}

$\mathrm{SD}=$ standard deviation. $\mathrm{IQR}=$ interquartile range.

$\mathrm{x}^{2}$ test used to compare categorical variables, one-way analysis of variance used to compare continuous variables. All variables were significantly associated with the type of fluid resuscitation; at least one of the comparisons between groups was significant $(\mathrm{P}<0.001)$. performed separate multilevel multivariable logistic regressions and included a random intercept term that varies at the level of each hospital. The random intercept accounts for correlation of patients within hospitals. To meet the minimum suggested size of each cluster in this type of model to reduce bias, ${ }^{24}$ only hospitals with sufficient patients $(\mathrm{n} \geq 50)$ were included. Models were adjusted using the Charlson comorbidity index and all demographic, and procedure related variables. Adjusted odds ratios, 95\% confidence intervals, and $\mathrm{P}$ values are reported and used together as a measure of overall significance.

Sensitivity-As comorbidity adjustment is a crucial part of our analysis we tested the sensitivity of using the Charlson comorbidity index to an alternative approach for which we used individual Elixhauser comorbidities. Elixhauser comorbidities for this analysis were selected by clinical relevance and included complicated and uncomplicated hypertension, chronic pulmonary disease, diabetes with and without complications, congestive heart failure, valvular disease, pulmonary circulatory disease, peripheral vascular disease, hypothyroidism, chronic renal failure, liver disease, coagulopathy, fluid and electrolyte disorder, chronic blood loss anemia, and deficiency anemia.

All analyses were performed in SAS v9.3 statistical software (SAS Institute, Cary, NC, USA). The SAS procedure GLIMMIX was used for multilevel regression analyses.

\section{Results}

After applying all exclusion criteria the final study sample included 1051441 patients from 510 hospitals with a range of one to 23138 elective total hip or knee arthroplasties per hospital. Hydroxyethyl starch was used in $4.2 \%(n=43732)$ of procedures, while albumin was used in $0.8 \%(n=8022)$; the group in whom neither was used comprised $95.1 \%(n=999687)$.

\section{Univariable results}

Patients who received hydroxyethyl starch were moderately younger (65.4 years old) than patients who received albumin (66.4 years) or neither of the two colloids (65.8 years). The use of hydroxyethyl starch in our sample dropped from $4.5 \%$ in 2012 to $3.3 \%$ in 2013, while albumin use rose from $0.9 \%$ to $1.2 \%$ in the same time. Median dosage for both hydroxyethyl starch and albumin was $500 \mathrm{~mL}$ (interquartile range 500-500 and 250-500 mL, respectively). Notably, transfusions were more commonly administered in patients who received hydroxyethyl starch (24.5\%) and albumin $(33.9 \%)$ compared with patients who received neither (15.2\%). Patient demographics, healthcare, and procedure related variables are listed in table 1. Although the median Charlson comorbidity index was similar in those who received hydroxyethyl starch and albumin compared with those who received neither colloid, a detailed breakdown by individual comorbidities demonstrates higher prevalence of most diseases in the albumin group. Comorbidities by patient groups are summarized in table 2 . 


\begin{tabular}{|c|c|c|c|}
\hline & $\begin{array}{l}\text { Hydroxyethyl } \\
\operatorname{starch}(n=43732)\end{array}$ & $\begin{array}{l}\text { Albumin } \\
(n=8022)\end{array}$ & $\begin{array}{l}\text { Neither } \\
(\mathrm{n}=999687)\end{array}$ \\
\hline $\begin{array}{l}\text { Median (IQR) Charlson comorbidity } \\
\text { index }\end{array}$ & $0(0-1)$ & $0(0-1)$ & $0(0-1)$ \\
\hline \multicolumn{4}{|l|}{ Elixhauser comorbidity grouping: } \\
\hline Congestive heart failure & $1660(3.8)$ & $444(5.5)$ & $29922(3.0)$ \\
\hline Valvular disease & $2139(4.9)$ & $470(5.9)$ & $46668(4.7)$ \\
\hline Pulmonary circulation disease & $498(1.1)$ & $143(1.8)$ & $11908(1.2)$ \\
\hline Peripheral vascular disease & $1319(3.0)$ & 307 (3.8) & $26275(2.6)$ \\
\hline Paralysis & $158(0.4)$ & $49(0.6)$ & $3298(0.3)$ \\
\hline Other neurological disorders & $1966(4.5)$ & $403(5.0)$ & $40601(4.1)$ \\
\hline Chronic pulmonary disease & $7164(16.4)$ & $1453(18.1)$ & $158648(15.9)$ \\
\hline Diabetes, no chronic complications & $7743(17.7)$ & $1506(18.8)$ & $189618(19.0)$ \\
\hline Diabetes, chronic complications* & $751(1.7)$ & $160(2.0)$ & $16896(1.7)$ \\
\hline Hypothyroidism & $6704(15.3)$ & $1389(17.3)$ & $157863(15.8)$ \\
\hline Chronic renal failure & $1813(4.1)$ & $527(6.6)$ & $42356(4.2)$ \\
\hline Hypertension, uncomplicated & $27400(62.7)$ & $4962(61.9)$ & $636421(63.7)$ \\
\hline Hypertension, complicated & $2162(4.9)$ & $618(7.7)$ & $51440(5.1)$ \\
\hline Liver disease & $468(1.1)$ & $135(1.7)$ & $10500(1.1)$ \\
\hline Chronic peptic ulcer disease* & $30(0.1)$ & $4(0.1)$ & $496(0.1)$ \\
\hline HIV/AIDS & $29(0.1)$ & $12(0.2)$ & $515(0.1)$ \\
\hline Lymphoma & $177(0.4)$ & $44(0.5)$ & $3126(0.3)$ \\
\hline Metastatic cancer & $116(0.3)$ & $42(0.5)$ & $2161(0.2)$ \\
\hline Solid tumor without metastasis & $585(1.3)$ & $121(1.5)$ & $11124(1.1)$ \\
\hline $\begin{array}{l}\text { Rheumatoid arthritis or collagen } \\
\text { vascular disease }\end{array}$ & $2115(4.8)$ & $471(5.9)$ & $47774(4.8)$ \\
\hline Coagulopathy & $1249(2.9)$ & $363(4.5)$ & $25301(2.5)$ \\
\hline Obesity* & $10032(22.9)$ & $1806(22.5)$ & $225086(22.5)$ \\
\hline Weight loss & $316(0.7)$ & $110(1.4)$ & $6634(0.7)$ \\
\hline Fluid and electrolyte disorder & $4586(10.5)$ & $1209(15.1)$ & $101163(10.1)$ \\
\hline Chronic blood loss anemia & $1263(2.9)$ & $177(2.2)$ & $20766(2.1)$ \\
\hline Deficiency anemia & $7421(17.0)$ & $1841(22.9)$ & $174430(17.4)$ \\
\hline Alcohol misuse & $293(0.7)$ & $73(0.9)$ & $5410(0.5)$ \\
\hline Drug misuse & $197(0.5)$ & $58(0.7)$ & $6033(0.6)$ \\
\hline Psychosis & $970(2.2)$ & $204(2.5)$ & $20136(2.0)$ \\
\hline Depression & $6614(15.1)$ & $1172(14.6)$ & $135137(13.5)$ \\
\hline \multicolumn{4}{|l|}{ Other: } \\
\hline Sleep apnea & $5316(12.2)$ & $861(10.7)$ & $109957(11.0)$ \\
\hline \multicolumn{4}{|c|}{$\begin{array}{l}\text { IQR=interquartile range. } \\
x^{2} \text { test used to compare categorical variables, Kruskal-Wallis test for Charlson comorbidity index. All variables } \\
\text { (except diabetes with chronic complications, chronic peptic ulcer disease, and obesity) were significantly } \\
\text { associated with the type of fluid resuscitation; at least one of the comparisons between groups was significan } \\
(P<0.001) \text {. } \\
{ }^{*} \text { No significant differences between groups. }\end{array}$} \\
\hline
\end{tabular}

Primary and secondary outcome variables

Acute renal failure was reported in $1.7 \%$ of patients who received hydroxyethyl starch, $3.4 \%$ of patients who received albumin, and $1.4 \%$ of those who received neither $(\mathrm{P}<0.001$; table 3$)$. Thromboembolic complications were less frequent in patients who received hydroxyethyl starch and more frequent in patients who received albumin, while cardiac complications and pulmonary complications were higher for either hydroxyethyl starch or albumin compared with the group who received neither. Patients who received albumin were more commonly admitted to an intensive care unit (14.9\%) than those who received hydroxyethyl starch $(7.8 \%)$ or neither $(6.9 \%)(\mathrm{P}<0.001)$. Similar patterns could be observed for mechanical ventilation and cost of hospitalization. The difference in length of hospital stay, while statistically significant, was likely of limited clinical significance. All univariable results are summarized in table 3.

\section{Multilevel logistic regression analysis}

The multilevel model used data on 1050741 procedures after excluding 39 hospitals because of low numbers of procedures $(<50)$; the number of procedures per hospital now ranged from 51 to 23138. After controlling for covariates as detailed in table 4, we found that perioperative use of hydroxyethyl starch was associated with higher adjusted odds for acute renal failure (odds ratio 1.23 (95\% confidence interval 1.13 to 1.34)) compared with no colloid use. This association was more pronounced for albumin (odds ratio 1.56 (1.36 to 1.78$)$ ). Compared with crystalloid administration, hydroxyethyl starch was not associated with increased odds of thromboembolic complications (odds ratio 0.89 (0.76 to 1.05)) whereas albumin was (odds ratio 1.47 (1.16 to 1.87)). Compared with patients who received neither colloid, adjusted odds for cardiac complications, pulmonary complications, and combined complications were increased for both hydroxyethyl starch (odds ratios 1.22 (1.13 to 1.31), 1.22 (1.11 to 1.33 ), and 1.20 (1.15 to 1.25$)$, respectively) and for albumin (odds ratios 1.37 (1.19 to 1.57), 1.82 (1.58 to 2.10), and 1.48 (1.37 to 1.60), respectively). The adjusted odds for an intensive care unit admission was also increased for perioperative hydroxyethyl starch (odds ratio 1.53 (1.45 to 1.60)) and for albumin (2.45 (2.26 to 2.65)) compared with use of neither. In the sensitivity analysis where specific comorbidities were included in the model, instead of the Charlson comorbidity index, results did not significantly differ. $\mathrm{C}$ statistics ranged from 0.71 to 0.82 in the reported models, indicating acceptable to good model discrimination.

\section{Discussion \\ Principal findings}

In this large retrospective study looking at data from more than a million elective hip and knee arthroplasties, we found an over $20 \%$ increase in the odds for acute renal failure after perioperative use of hydroxyethyl starch and an over 50\% increase after administration of albumin compared with administration of neither colloid. After controlling for covariates, use of hydroxyethyl starch and of albumin did show an increased association with most studied complications when compared with patients who received neither. Additionally, we observed a drop in hydroxyethyl starch use in the year 2013, while at the same time albumin use increased. While a causal relationship remains elusive, we conclude from our study that a higher risk of adverse renal and other organ system events associated with hydroxyethyl starch as observed in critically ill patients might also apply to the elective perioperative setting. Further, we could demonstrate that another viable alternative, namely albumin, might also be associated with increased perioperative risks. This in turn calls for further discussions and prospective studies regarding 


\begin{tabular}{|c|c|c|c|}
\hline & $\begin{array}{l}\text { Hydroxyethyl starch } \\
(\mathrm{n}=43732)\end{array}$ & $\begin{array}{l}\text { Albumin } \\
(n=8022)\end{array}$ & $\begin{array}{l}\text { Neither } \\
(n=999687)\end{array}$ \\
\hline \multicolumn{4}{|l|}{ Primary outcome variables } \\
\hline Acute renal failure & $764(1.7)$ & $273(3.4)$ & $13857(1.4)$ \\
\hline Thromboembolic complications & $182(0.4)$ & $73(0.9)$ & $6631(0.7)$ \\
\hline Cardiac complications & $1087(2.5)$ & $238(3.0)$ & $21619(2.2)$ \\
\hline Pulmonary complications & $642(1.5)$ & $221(2.8)$ & $13193(1.3)$ \\
\hline Combined complications* & $3289(7.5)$ & $916(11.4)$ & $67125(6.7)$ \\
\hline \multicolumn{4}{|l|}{ Secondary outcome variables } \\
\hline In-hospital mortality & $45(0.1)$ & $13(0.2)$ & $565(0.1)$ \\
\hline Admission to intensive care unit & $3391(7.8)$ & $1196(14.9)$ & $68514(6.9)$ \\
\hline Mechanical ventilation & $321(0.7)$ & $84(1.0)$ & $2590(0.3)$ \\
\hline Median (IQR) length of hospital stay (days) & $3(3-4)$ & $3(3-4)$ & $3(3-4)$ \\
\hline Median (IQR) cost of hospitalization (\$) & $16191(13428-19615)$ & $18596(14815-23191)$ & $15057(12398-18551)$ \\
\hline \multicolumn{4}{|c|}{$\begin{array}{l}\text { IQR=interquartile range. } \\
x^{2} \text { test used to compare categorical variables, Kruskal-Wallis test for length of hospital stay and cost of hospitalization. All variables were significantly } \\
\text { associated with the type of fluid resuscitation; at least one of the comparisons between groups was significant ( } P<0.001) \text {. } \\
\text { *Composite variable (pulmonary embolism, deep vein thrombosis, cerebrovascular events, other pulmonary complications, sepsis, cardiac complications, } \\
\text { atrial fibrillation, pneumonia, other infections, acute renal failure, gastrointestinal complications, myocardial infarction, and mortality). }\end{array}$} \\
\hline
\end{tabular}

the safety and alternatives of these solutions in perioperative medicine.

\section{Comparison with existing literature}

The debate around crystalloid versus colloid recently reignited after two studies analyzing the use of hydroxyethyl starch versus crystalloids in critically ill patients $\left(6 \mathrm{~S}^{6}\right.$ and $\left.\mathrm{CHEST}^{5}\right)$ reported an increase in adverse renal events and need for renal replacement therapy. In the following year systematic reviews and studies on both hydroxyethyl starch and albumin versus crystalloids for fluid resuscitation were published, with the majority demonstrating an increase in adverse renal outcomes. ${ }^{341025-27}$ For example, the CRISTAL trial, a multicenter randomized trial comparing intravenous colloids and crystalloids for hypovolemic shock in intensive care units, failed to show convincing evidence for either mortality or renal outcome benefit while utilizing data from over 2800 patients. ${ }^{28}$ The SAFE trial comparing the use of albumin and saline fluids among 6997 patients in intensive care showed a marginal, non-significant increase in both duration of renal replacement therapy and mechanical ventilation for the albumin group. ${ }^{29}$ However, these studies did not allow for the extrapolation of findings to perioperative fluid resuscitation during elective procedures. Recently, a small randomized trial including 40 hip arthroplasty patients reported no increased risk for nephrotoxicity associated with hydroxyethyl starch, ${ }^{30}$ while a larger retrospective study of a clinical dataset from over 25000 non-cardiac surgery patients found an increased risk for acute kidney injury associated with hydroxyethyl starch of about $21 \%,{ }^{31}$ similar to our findings. This might reflect the problem of adequate power found with studies of small sample size when assessing risks for rare events.

Our study features a cohort of over one million elective, lower extremity joint replacements from different hospitals across the United States. In concordance with previous publications in the critical care setting, we identified an increased risk for acute renal failure and complications not only for hydroxyethyl starch but also for albumin 5\% in elective surgical procedures. The few thus far available results on the topic are not uniform among different patient populations. For example, in a single center, retrospective medical record analysis comparing albumin and hydroxyethyl starch after orthotopic liver transplants, the authors saw a threefold

Table 4 | Results from multilevel logistic regression model* for primary outcomes and intensive care unit admission among patients undergoing elective total hip and knee arthroplasties grouped by their receipt of perioperative fluid resuscitation with hydroxyethyl starch $6 \%$ or with albumin $5 \%$ versus neither

\begin{tabular}{|c|c|c|c|c|c|}
\hline \multirow[b]{2}{*}{ Outcomes } & \multicolumn{2}{|c|}{ Hydroxyethyl starch $v$ neither } & \multicolumn{2}{|l|}{ Albumin $v$ neither } & \multirow[b]{2}{*}{ C statistic } \\
\hline & Odds ratio $(95 \% \mathrm{Cl})$ & $P$ value & Odds ratio $(95 \% \mathrm{Cl})$ & $P$ value & \\
\hline Acute renal failure & $1.23(1.13$ to 1.34$)$ & $<0.001$ & $1.56(1.36$ to 1.78$)$ & $<0.001$ & 0.79 \\
\hline Thromboembolic complications & 0.89 (0.76 to 1.05$)$ & 0.153 & $1.47(1.16$ to 1.87$)$ & 0.002 & 0.71 \\
\hline Cardiac complications & $1.22(1.13$ to 1.31$)$ & $<0.001$ & 1.37 (1.19 to 1.57$)$ & $<0.001$ & 0.78 \\
\hline Pulmonary complications & $1.22(1.11$ to 1.33$)$ & $<0.001$ & $1.82(1.58$ to 2.10$)$ & $<0.001$ & 0.71 \\
\hline Combined complicationst & $1.20(1.15$ to 1.25$)$ & $<0.001$ & $1.48(1.37$ to 1.60$)$ & $<0.001$ & 0.72 \\
\hline Intensive care unit admission & $1.53(1.45$ to 1.60$)$ & $<0.001$ & 2.45 (2.26 to 2.65$)$ & $<0.001$ & 0.82 \\
\hline
\end{tabular}

*Multilevel logistic regression analysis adjusted for age, sex, ethnicity, procedure group, discharge year, insurance status, anesthesia type, peripheral block, transfusion, comorbidity index, sleep apnea.

†Aggregate variable (pulmonary embolism, deep vein thrombosis, cerebrovascular events, other pulmonary complications, sepsis, cardiac complications, atrial fibrillation, pneumonia, other infections, acute renal failure, gastrointestinal complications, myocardial infarction, mortality). 
increased risk for acute kidney injury for hydroxyethyl starch versus albumin. ${ }^{32}$ In contrast, we found a higher risk for acute renal failure in orthopedic patients who received perioperative albumin. This difference may at least in part be explained by differences in doses, patient cohorts, and organ pathology, as a relationship between renal and hepatic function for liver transplantations has been described. ${ }^{33}$ Similar to our observation, the clinicians in the above study used hydroxyethyl starch more often than albumin. Reasons for this might include the lower cost of hydroxyethyl starch, ${ }^{34}$ clinicians' specialty, location of practice, clinical scenario, and marketing effcets. ${ }^{35}$

Particularly for patients undergoing elective hip and knee arthroplasties, prospective studies might shed some light into the pathogenesis of the complications under study, as the exact mechanisms are not yet fully understood. One potential mechanism for adverse outcomes that could be modified by the administration of colloids is the unique pathophysiology associated with hip and knee arthroplasties. The intravasation of bone, cement, and marrow debris during the procedure leads to embolization of this material into various organ systems. ${ }^{36} 37$ This in turn may lead to tissue injury. Emboli into the lungs, for example, can lead to pulmonary edema, right heart strain, and arrhythmias. Changes in vascular permeability may promote tissue edema that may worsen when colloids are administered.

We also identified a decrease in the use of hydroxyethyl starch in the most recent study period and a concomitant increase in albumin infusion rates. While speculative, this may reflect a reaction of practitioners to the above cautionary publications and subsequent warnings by government agencies. The increase in the use of albumin and the finding that it is associated with greater risk for adverse outcomes deserve additional study. A post-hoc analysis in which we directly compared albumin with hydroxyethyl starch for all outcomes in the study (see appendix 2 in the online data supplement) showed albumin to be associated with $22 \%$ increased odds for acute renal failure (odds ratio 1.22 (95\% confidence interval 1.04 to 1.42)) and up to $83 \%$ increased odds for thromboembolic complications (odds ratio 1.83 (1.39 to 2.42)). However, caution in interpretation is warranted as there might be comorbidity confounders unaccounted for.

\section{Strengths and limitations of this study}

Studies investigating the effect of infused fluid type on outcomes seem to be especially burdened by the limitations related to confounding. Indeed, the validity of conclusions drawn from previous publications concerning this topic has been questioned. Some authors have pointed out that the VISEP ${ }^{7}$ and $6 \mathrm{~S}^{6}$ trials, investigating volume resuscitation in a critical care setting, recruited patients up to 24 hours after diagnosis of sepsis or septic shock, therefore suffering from protocols not reflecting clinical reality. ${ }^{38}$ We aimed to avoid such bias by limiting the inclusion of patients to those who received either hydroxyethyl starch or albumin on the day of surgery or on the first postoperative day-that is, a strictly defined perioperative period. However, other limitations most certainly apply.

An important limitation of our analysis is the lack of information on the causal relation between colloid use and outcomes. This is in part because the Premier database does not provide clinical detail (such as amount of blood loss, serum albumin levels, or hemodynamic data). This lack of clinical detail is also reflected in the use of ICD-9 coding, which does not allow for the determination of severity of renal dysfunction. This is a disadvantage compared with clinical trials, in which more nuanced outcomes such as changes in creatinine level can be studied. Exploratory analysis using the outcome of renal replacement therapy, often used in clinical studies, was not feasible because of its low incidence, likely explainable by the elective patient population investigated. This further emphasizes the need for more detailed data collection processes and registries in the elective perioperative setting.

For some variables we were able to use proxies to reduce the effect of missing detailed clinical information. By accounting for blood transfusions given we attempted to address lacking information on blood loss (although imperfect) by means of a surrogate marker.

Further, we focused our analysis on hydroxyethyl starch 6\% (Hespan) and albumin 5\% and did not include alternate colloids such as tetrastarch, pentastarch, dextran, or gelatin solutions. This is important as systematic reviews did report no risk for adverse renal effects when evaluating randomized perioperative trials investigating different colloids, such as tetrastarch or hydroxyethyl starch derived from waxy maize. ${ }^{2739}$ While these reviews were sponsored by hydroxyethyl starch manufacturers and have been criticized on multiple accounts, some see the lower dose used in surgical patients as a possible cause for lower rates of renal complications. ${ }^{13}$ Similarly, clinical trials (such as CHEST $^{5}$ ) and their direct applicability to surgical patients have been criticized on the basis of the perceived high dose that patients received. ${ }^{12}$ While the question of a "correct" dose has been raised on many occasions, to date no clear evidence has emerged to answer this issue. ${ }^{10}$ Our attempts to investigate and control for the administered dose were limited to a univariate analysis because multivariable models based on various dose groups produced limited observations in some subgroups, rendering the models not robust enough. This demonstrates that, even in population based studies far outperforming most other studies in terms of sample size, observed outcomes might be too scarce to draw even preliminary conclusions.

While our multivariable analysis did account for comorbidity burden and blood product transfusions, we cannot rule out indication bias and potential residual confounding. To further minimize the effects of indication bias, we only included elective patients undergoing two procedures (hip and knee arthroplasty) that are highly standardized and relatively homogenous. Finally, potential bias remains because of lack of clinical information, coding errors, or other unforeseen variables we could not measure. However, some of 
these errors, particularly coding errors, are expected to be equally distributed among groups, thus limiting their effect on comparative results. We expect the same mechanism to apply to the lack of clinical data behind the ICD-9 codes.

Interestingly, we identified differences in the proportion of anesthetic techniques used between study groups. Specifically, the use of peripheral nerve blocks was nearly twice as high in patients treated with hydroxyethyl starch as those treated with albumin. While our statistical model accounts for these factors in respect to the outcomes studied, this finding points toward the possibility of different clinical practices that the various groups were exposed to. This in turn raises the question whether certain novel, outdated, or alternative treatment approaches (anesthetic practice in this case) are associated with the use of other interventions such as the choice of fluid management, as shown here. This relation may exist for other variables as well. Our use of a multilevel analysis taking into account hospital level data was designed to at least partly address the issue of practice variations between institutions.

As we used data from patients undergoing their procedures in the United States, our results might not be generalizable to other countries, especially because of differences in the type of hydroxyethyl starches used in the US versus those used in Europe ${ }^{40}$ and other Western countries. European practice may differ because of tendency to use lower molecular weight preparations compared with the US and highly substituted solutions that have been associated with increased tissue deposition and coagulopathy..$^{40}$ How these differences in type and use relate to the safety of synthetic colloids requires further study.

\section{Conclusions and implications}

Our study results show the need for further studies. First, retrospective studies are needed to validate or challenge our findings, possibly in other settings (such as other procedures) using other methodologies (such as propensity score analysis) in other databases such as the Truven MarketScan database ${ }^{41}$ (containing information on over 196 million patients with employer-provided health insurance). Further, well designed prospective studies are needed, which initially do not have to be randomized trials. Prospective observational studies collecting a large number of variables of interest may provide additional information. A multicenter clinical registry on colloid use in elective surgery may be necessary as the debate on the safety of hydroxyethyl starch and other colloids continues and affects many care settings. This would entail detailed capture of variables related to the intervention under study (such as colloid dose, timing of administration) and the outcomes of interest (such as development of renal function). Additional data on safety would greatly benefit daily clinical practice as the use of colloids should follow a conscious decision making process and should not occur as per routine.

Using population based data on elective hip and knee arthroplasties, we were able to identify an association with an increase in the odds for acute renal failure of $20 \%$ when hydroxyethyl starch and $50 \%$ when albumin was used in the setting of elective orthopedic surgery, compared to no such use. The odds for most other studied complications were also increased. Given these results, the recent trend of a reduced use of hydroxyethyl starch in favor of albumin, if indeed related, may be misguided. Despite limitations of our investigation, these findings raise the question of the utility of both hydroxyethyl starch and albumin in the perioperative setting. Randomized clinical trials and additional prospective studies are urgently needed to shed light into the safety and role of colloid solutions in perioperative medicine.

\section{AUTHOR AFFILIATIONS}

'Department of Anesthesiology, Hospital for Special Surgery, New York, NY 10021, USA; Department of Anesthesiology, Perioperative Medicine and Intensive Care Medicine, Paracelsus Medical University, 5020 Salzburg, Austria

2Institute for Healthcare Delivery Science, Department of Population Health Science and Policy; Department of Medicine, Icahn School o Medicine at Mount Sinai, New York, NY 10029, USA

${ }^{3}$ Institute for Healthcare Delivery Science, Department of Population Health Science and Policy, Icahn School of Medicine at Mount Sinai, New York

4Weill Cornell Medical College, Department of Healthcare Policy and Research, New York; Department of Anesthesiology, Hospital for Special Surgery, New York; Department of Anesthesiology, Perioperative Medicine and Intensive Care Medicine, Paracelsus Medical University, Salzburg

Contributor: All authors designed the study and attained the Premie Perspective database. RR, MO, and IP analyzed data under guidance of SGM and MM. All authors contributed to the interpretation of the results, reviewed and approved the final manuscript, had full access to all the data in the study, and gave their final approval of the submitted manuscript and agreed to be accountable for all aspects of the work. MO and RR take responsibility for the integrity of the data and the accuracy of the data analysis. SGM and MM are the study guarantors.

Funding: SGM is funded by the Anna Maria and Stephen Kellen Career Development Award, New York. RR and MM are partially funded by Cardiothoracic Surgical Trials Network (CTSN) and the Tisch Cancer Institute at the Icahn School of Medicine at Mount Sinai, New York.

The study sponsors had no role in the design and conduct of the study; in the collection, analysis, and interpretation of the data; or in the preparation, review, or approval of the manuscript. The views expressed in this article are those of the authors and do not necessarily represent the views of the sponsors or authors' affiliated institutions.

Competing interests: All authors have completed the ICMJE uniform disclosure form at www.icmje.org/coi_disclosure.pdf and declare: no support from any organization for the submitted work; no financial relationships with any organizations that might have an interest in the submitted work in the previous three years; no other relationships or activities that could appear to have influenced the submitted work

Ethical approval: This study was exempt from consent requirements by the Hospital for Special Surgery Institutional Review Board (No 2012-050-CR2) as the data meet the requirements of de-identification as defined by the Health Insurance Portability and Accountability Act.

Data sharing: Data was purchased from Premier and is restricted for this project and cannot be shared because of these restrictions on use of data. Syntax is available from the corresponding author (memtsoudiss@hss.edu).

Transparency: The senior author, SGM affirms that the manuscript is an honest, accurate, and transparent account of the study being reported; that no important aspects of the study have been omitted; and that any discrepancies from the study as planned (and, if relevant, registered) have been explained. 
This is an Open Access article distributed in accordance with the Creative Commons Attribution Non Commercial (CC BY-NC 4.0) license, which permits others to distribute, remix, adapt, build upon this work non-commercially, and license their derivative works on different terms, provided the original work is properly cited and the use is noncommercial. See: http://creativecommons.org/licenses/by-nc/4.0/.

1 Perel P, Roberts I, Ker K. Colloids versus crystalloids for fluid resuscitation in critically ill patients. Cochrane Database Syst Rev 2013;2:CD000567. doi:10.1002/14651858.CD000567.pub6.

2 Bunn F, Trivedi D. Colloid solutions for fluid resuscitation. Cochrane Database Syst Rev 2012;7:CD001319. doi:10.1002/14651858. CD001319.pub5.

3 Haase N, Perner A, Hennings LI, Siegemund M, Lauridsen B, Wetterslev M, et al. Hydroxyethyl starch $130 / 0.38-0.45$ versus crystalloid or albumin in patients with sepsis: systematic review with meta-analysis and trial sequential analysis. BMJ 2013;346:f839.

4 Zarychanski R, Abou-Setta AM, Turgeon AF, Houston BL, McIntyre L, Marshall JC, et al. Association of hydroxyethyl starch administration with mortality and acute kidney injury in critically ill patients requiring volume resuscitation: a systematic review and meta-analysis. JAMA 2013;309:678-88

5 Myburgh JA, Finfer S, Bellomo R, Billot L, Cass A, Gattas D, et al. Hydroxyethyl starch or saline for fluid resuscitation in intensive care. N Engl J Med 2012;367:1901-11.

6 Perner A, Haase N, Guttormsen AB, Tenhunen J, Klemenzson G, Åneman A, et al. Hydroxyethyl starch 130/0.42 versus Ringer's acetate in severe sepsis. N Engl / Med 2012;367:124-34

7 Brunkhorst FM, Engel C, Bloos F, Meier-Hellmann A, Ragaller M, Weiler N, et al. Intensive insulin therapy and pentastarch resuscitation in severe sepsis. N Engl J Med 2008;358:125-39.

8 US Food and Drug Administration. Hydroxyethyl starch solutions: FDA safety communication-boxed warning on increased mortality and severe renal injury and risk of bleeding. 2013. www.fda.gov/safety/ medwatch/safetyinformation/safetyalertsforhumanmedicalproducts/ ucm358349.htm.

9 European Medicines Agency. PRAC confirms that hydroxyethyl-starch solutions (HES) should no longer be used in patients with sepsis or burn injuries or in critically ill patients. 2013. www.ema.europa.eu/ docs/en_GB/document_library/Press_release/2013/10/ WC500151964.pdf.

10 Mutter TC, Ruth CA, Dart AB. Hydroxyethyl starch (HES) versus other fluid therapies: effects on kidney function. Cochrane Database Syst Rev 2013;7:CD007594. doi:10.1002/14651858.CD007594.pub3.

11 Bellomo R, Bion J, Finfer S, Myburgh J, Perner A, Reinhart K. Open letter to the executive director of the European Medicines Agency concerning the licensing of hydroxyethyl starch solutions for fluid resuscitation. Br J Anaesth 2014;112:595-600.

12 Coriat P, Guidet B, de Hert S, Kochs E, Kozek S, Van Aken H. Counter statement to open letter to the executive director of the European Medicines Agency concerning the licensing of hydroxyethyl starch solutions for fluid resuscitation. Br J Anaesth 2014;113:194-5.

13 Irwin MG, Gan TJ. Volume therapy with hydroxyethyl starches: are we throwing the anesthesia baby out with the intensive care unit bathwater? Anesth Analg 2014;119:737-9.

14 Skhirtladze K, Base EM, Lassnigg A, Kaider A, Linke S, Dworschak M, et al. Comparison of the effects of albumin $5 \%$, hydroxyethyl starch $130 / 0.46 \%$, and Ringer's lactate on blood loss and coagulation after cardiac surgery. BrJ Anaesth 2014;112:255-64.

15 Roberts I, Blackhall K, Alderson P, Bunn F, Schierhout G. Human albumin solution for resuscitation and volume expansion in critically ill patients. Cochrane Database Syst Rev 2011;:CD001208. doi:10.1002/14651858.CD001208.pub4

16 Premier. Premier Perspective Database. https://www.premierinc.com/ transforming-healthcare/healthcare-performance-improvement/ premier-research-services/.

17 Broderick JS, Henley MB. An introduction to orthopaedic coding and billing. J Orthop Trauma 2014;28(suppl 9):S12-4. doi:10.1097/ BOT.0000000000000178.

18 McDonald JS, McDonald RJ, Fan J, Kallmes DF, Lanzino G, Cloft HJ. Comparative effectiveness of ruptured cerebral aneurysm therapies: propensity score analysis of clipping versus coiling. AJNR Am J Neuroradiol 2014;35:164-9.

19 Rothberg MB, Pekow PS, Priya A, Zilberberg MD, Belforti R, Skiest D, et al. Using highly detailed administrative data to predict pneumonia mortality. PLoS One 2014;9:e87382.
20 Memtsoudis SG, Danninger T, Rasul R, Poeran J, Gerner P, Stundner O, et al. Inpatient falls after total knee arthroplasty: the role of anesthesia type and peripheral nerve blocks. Anesthesiology 2014; 120:551-63.

21 Quan H, Sundararajan V, Halfon P, Fong A, Burnand B, Luthi J-C, et al. Coding algorithms for defining comorbidities in ICD-9-CM and ICD-10 administrative data. Med Care 2005;43:1130-9.

22 Deyo RA, Cherkin DC, Ciol MA. Adapting a clinical comorbidity index for use with ICD-9-CM administrative databases. J Clin Epidemiol 1992:45:613-9.

23 Elixhauser A, Steiner C, Harris DR, Coffey RM. Comorbidity measures for use with administrative data. Med Care 1998;36:8-27.

24 Moineddin R, Matheson Fl, Glazier RH. A simulation study of sample size for multilevel logistic regression models. BMC Med Res Methodol 2007;7:34.

25 Patel A, Waheed U, Brett SJ. Randomised trials of $6 \%$ tetrastarch (hydroxyethyl starch 130/0.4 or 0.42) for severe sepsis reporting mortality: systematic review and meta-analysis. Intensive Care Med 2013;39:811-22.

26 Patel A, Laffan MA, Waheed U, Brett SJ. Randomised trials of human albumin for adults with sepsis: systematic review and meta-analysis with trial sequential analysis of all-cause mortality. BMJ 2014;349:g4561.

27 Van Der Linden P, James M, Mythen M, Weiskopf RB. Safety of modern starches used during surgery. Anesth Analg 2013;116:35-48.

28 Annane D, Siami S, Jaber S, Martin C, Elatrous S, Declère AD, et al. Effects of fluid resuscitation with colloids vs crystalloids on mortality in critically ill patients presenting with hypovolemic shock: the CRISTAL randomized trial. JAMA 2013;310:1809-17.

29 Finfer S, Bellomo R, Boyce N, French J, Myburgh J, Norton R. A comparison of albumin and saline for fluid resuscitation in the intensive care unit. N Engl I Med 2004;350:2247-56.

30 Kancir ASP, Pleckaitiene L, Hansen TB, Ekeløf NP, Pedersen EB. Lack of nephrotoxicity by $6 \%$ hydroxyethyl starch $130 / 0.4$ during hip arthroplasty: a randomized controlled trial. Anesthesiology 2014; 121:948-58.

31 Kashy BK, Podolyak A, Makarova N, Dalton JE, Sessler DI, Kurz A. Effect of hydroxyethyl starch on postoperative kidney function in patients having noncardiac surgery. Anesthesiology 2014;121:730-9.

32 Hand WR, Whiteley JR, Epperson TI, Tam L, Crego H, Wolf B, et al. Hydroxyethyl starch and acute kidney injury in orthotopic liver transplantation: a single-center retrospective review. Anesth Analg 2015;120:619-26.

33 Tinti F, Umbro I, Meçule A, Rossi M, Merli M, Nofroni I, et al. RIFLE criteria and hepatic function in the assessment of acute renal failure in liver transplantation. Transplant Proc 2010;42:1233-6.

34 Donnelly AJ. Albumin/hetastarch drug utilization review in an operating room pharmacy. Drug Intell Clin Pharm 1987;21:286-9.

35 Miletin MS, Stewart TE, Norton PG. Influences on physicians' choices of intravenous colloids. Intensive Care Med 2002;28:917-24.

36 Donaldson AJ, Thomson HE, Harper NJ, Kenny NW. Bone cement implantation syndrome. Br J Anaesth 2009;102:12-22.

37 Memtsoudis SG, Salvati EA, Go G, Ma Y, Sharrock NE. Perioperative pulmonary circulatory changes during bilateral total hip arthroplasty under regional anesthesia. Reg Anesth Pain Med 2010;35:417-21.

38 Chappell D, Jacob M. Hydroxyethyl starch-the importance of being earnest. Scand I Trauma Resusc Emerg Med 2013;21:61

39 Martin C, Jacob M, Vicaut E, Guidet B, Van Aken H, Kurz A. Effect of waxy maize-derived hydroxyethyl starch 130/0.4 on renal function in surgical patients. Anesthesiology 2013;118:387-94.

40 Dieterich H-J. Recent developments in European colloid solutions J Trauma 2003;54:S26-30. doi:10.1097/01.TA.0000028408.13858.7A.

41 Danielson E. White paper: health research data for the real world: the MarketScan databases. Truven Health Analytics, 2014. http:// truvenhealth.com/Portals/0/Users/031/31/31/PH_13434 0314 MarketScan WP web.pdf.

Appendix 1: Definitions of outcomes and comorbidities. Appendix 2: Results from direct comparison of hydroxyethyl $\operatorname{starch} v$ albumin 